\title{
Moist Life: Artistic Teaching Approach of Music Culture Liu Chao
}

Linyi University, Yishui, Shandong, 276400

\section{Key words: Music culture; Artistic; Teaching way}

\begin{abstract}
With the deepening of music reform in modern society, specific music teaching methods have made big progress and innovation, but in teaching process, there are some prominent problems, which play an important role in effectively solving the problem of how to promote the art development of music teaching. The reasonable use of art technique has a key role in realizing the art of music teaching, and at the same time the artistic innovation of relevant teaching content, teaching methods and the relationship between teachers and students have important influence on the realization of music aesthetics and music teaching.
\end{abstract}

\section{INTRODUCTION}

With the continuous development of music teaching in modern society, the artistic innovation of music teaching is the main reflection of the effective use of music teaching method and its inherent laws in the process of teaching. Artistic music teaching in specific teaching helps to pass the visual perception of beauty. Due to traditional music teaching uses traditional music teaching method, it can't timely perform and out stand in aesthetic characteristics, and also lack artistic expression. Therefore, the teacher will stimulate the music classroom atmosphere by some vivid music works in the process of teaching, create a study environment which may contribute to artistic music teaching, so that the students can devote themselves to music learning under the support of positive state of mind, and promote the development of the diversity of artistic teaching of music culture.

\section{THE EXISTING PROBLEMS AND CONNOTATION IN ARTISTIC MUSIC TEACHING}

The reasonable use of artistic music teaching plays an important role for the aesthetics of music teaching. Realization of the art of music teaching in music teaching methods, rhythm, content and the relationship between teachers and students and the realization of the personalized development in music teaching have a role in promoting in the realization of music aesthetic and teaching purpose. Under certain conditions, realize the art of teaching is art teaching. In concrete music teaching, by using various artistic techniques, meet the implementation requirement for law and music itself value, under the influence of artistic music teaching, it will develop more scientifically and standardized direction. If in specific teaching process, we still adopt traditional teaching mode, and not conform to the condition of teaching art, and do not present our own music teaching aesthetic point of view in time, the teaching content is also lack of corresponding point of art. In music teaching, the most main and prominent problem of teaching methods lacks artistic quality. In specific music teaching, the existence of aesthetic characteristics and inherent nature do not get through in the whole teaching process, and the specific teaching method will also highlight its artistic connotation. Although music culture is a kind of art form, in music teaching, it lacks corresponding teaching form of art, and in some conditions, teaching method is not artistic, and the main reason is that many teachers now lack effective innovation in specific teaching methods, and they still uses old and traditional teaching methods in music teaching activities, and in music teaching content, also lack adequate artistry. The concrete teaching ability is insufficient in art embodied teaching process. In specific music teaching, realize art teaching methods and the purpose, means and influence of music teaching. Music ontology is the main body of music teaching content, and it is art work with specific meaning and value. Music teachers, in teaching, should reasonably 
use artistic elements, not just use dull or single way in music teaching, but learn to use the teaching method of beauty in the process of teaching in teaching content, be good at fuse those beautiful things into specific teaching activities, ascend teaching content's charm to the greatest extent, thus effectively achieve the goal of artistic music teaching.

\section{THE METHOD AND MEANS OF ARTISTIC TEACHING OF MUSIC CULTURE}

\section{A. The ratification of music teaching content}

For music teaching, it is essentially a teaching form of aesthetic tendency. Under certain conditions, this determines that music teaching must have the basic characteristics and connotation of art. In music teaching content, it must have certain aesthetic value and characteristics. The embodiment of music aesthetics and music spirit should be main factors of music teaching content. In music teaching process, regarding the choice of music works, choose those who have noble character and can edify sentiment direction, so that it can effectively realize the essence characteristic and the connotation of music teaching, and have important influence on improving the students' music aesthetic ability and related personality shaping, etc. At the same time we should also understand the music teaching content to achieve its artistic quality, not just let it have the corresponding artistic features on teaching content, which can conform to the requirements of certain artistic teaching development. In an actual artistic music teaching process, if the teacher explain very professionally the music theory knowledge and also has very high level of education, the students can't understand or don't understand the teacher's words, under certain conditions, the standard of art appreciation and aesthetic deviate from the cultivation of psychological characteristics. We can see that this kind of teaching method and effect in teaching content has no specific artistic characteristics. Music education is a kind of art education with aesthetic value, in concrete teaching process; teachers should, according to the actual need, effectively use aesthetic teaching, and take aesthetic as the core part of the whole teaching concept. On the choice of teaching content, conform to student's psychological characteristic and aesthetic level, be good at using those outstanding music heritage in concrete music teaching with a range of artistic and cultural value, and more classic music in music teaching work is blended among them, let the student fully feel the classic works' art culture breath in learning music, feel and taste the classics strong vitality, thus provide sufficient theoretical preparation to achieve the artistic teaching of music culture.

\section{B. The artistic way of teaching}

On the choice of specific teaching methods, rationally utilize the aesthetic rule of music teaching. According to music art's creative, intuitive and personalized features, propose change and innovation of targeted teaching methods, and according to the aesthetic psychological characteristics in music teaching situation, target put forward the corresponding music teaching form and situation aesthetic requirement. In teaching situation, make perfect scene so as to realize certain scene real, and effectively blend means and sentiment and scene cutting art state to achieve the purpose of effective visual and sound effects. Language analysis for concrete music teaching in the teaching of music must be good to let the students get the charm and joy of beauty, and make music elements pass some beautiful pictures of the music object for effective display. The purpose lays in the flow of music in people's minds, like flowing scenery, the effective combination of visual art and auditory art, effective flow this beautiful picture into the landscape with poetic language of art as well as the set off of beautiful picture. The key is that it also contains the students' rich emotional factors of artistic music, experience the beauty value and performance of artistic music conception, also effectively introduce to the students rich images of music art realm. 


\section{The artistic teaching pace}

The artistic teaching pace is also corresponding rhythm beauty under certain conditions. In the pursuit of art rhythm, the whole teaching process have a certain order and vivid music performance process of beauty, so as to promote music teaching process be with the change of rhythm and effectively promote teaching rhythm continuously in the direction of fast and vivid development of artistic expression. This rhythm beauty exists under certain conditions, which can effectively help the students with learning, and complete its internal creation process, laid an important role in student's physical health and the health of body and mind development. In teaching activities with rhythm, effectively infect students; let students understand the meaning of life and value from presenting the beauty of artistic conception of music art. Rhythm beauty pursuit also can promote students and teachers emotional and communication of thinking activity, and form a kind of harmony and unity between the art realms. In music teaching process, control the rhythm of music in a reasonable manner, and the important content of which is to pay attention to the psychological characteristics of students, be good at observation and analysis of students' existing cognitive regularity, scientifically and reasonably arrange and adjust music teaching steps and the time. If there is no innovation, take down to flat out straight way, the students of this teaching method can produce a certain sense of boring. In specific artistic music teaching process, achieve the effective combination of dynamic and static, tension relaxation and perfect coordination and the density, also pay attention to using a variety of contrast and transformation technique, enrich the teaching process and innovation expression, form a certain rhythm and the required rhythm with the formation of students' inner rhythm effective combination, thus form the perfect combination of the two kinds of rhythms and influence each other, and produce a certain required artistic performance to the rhythm of aesthetic feeling.

\section{Personalized music teaching}

In concrete music teaching, let students have art requirements of a certain personality needs. Teachers in specific teaching methods should have a certain personality, fully respect students' differences and personality in music teaching, and let them control more free and independent space. Teachers in the teaching have certain personality traits; actively show their own personality, so as to form its own personality under the guidance of student individuality formation of certain requirements. In concrete music teaching, although there is a unified specification of constraints, one of the most important things is to give full play to teachers' inner personality characteristics, which is reflected in the teaching of individuation in music teaching in a prominent artistic performance. Without personality in teaching, the teaching of the teaching content is lack of corresponding artistic charm. From traditional music teaching pattern, we can see that the traditional music teaching mode is the unified teaching mode and method. The whole class gives people a feeling of dull and boring. To analyze from the angle of students, they learn in such a teaching environment, not only the learning efficiency is not real, but also the learned knowledge is useless, which cannot be used for good practical application. And students in the teaching of diversification and individuation consciousness play an indelible effect, the teachers in concrete personalized teaching also lack corresponding personalized exploration, therefore, the teacher in artistic music teaching should make full use of personalized color, form independent personality, teaching ideas and methods, and give timely guide for student's personal cultivation, and form personalized characteristic of learning and innovative thinking. In students' real life and learning, they have their own independent living environment and study status, therefore in concrete teaching teachers should maximally arouse their subject consciousness, respect each student's individual 
character characteristic, give sufficient and actively guide and encourage them to participate in music creation, in the process of creation, concretely recognize their differences, and reasonably locate and perfect, to ensure that everyone has their own individual character style. The teacher should be good enough to create space for students to imagine, help students to have a clear understanding of personalized teaching so as to form aesthetic standard for personalized characteristic, thereby promote the improving of students' ability of individual creativity.

\section{CONCLUSION}

Music teaching, as the teachers effectively demonstrate process of music artistic charm, music need to follow certain aesthetic features of effective teaching process, and under the support of aesthetic characteristics, deepen the promotion of the development of artistic music teaching, so as to make the whole teaching process more tendency in aesthetic and artistic direction. In music teaching, not only embody the art of teaching content, and should have a certain artistic and aesthetic art of music teaching in concrete teaching methods, results and even teaching ideas, meet the requirements of a certain aesthetic regularity and teaching form in the whole teaching process which has been saturated with artistic aesthetic demand, so that they can more fully promote the development of music culture's art teaching requirements.

\section{REFERENCES}

[1] Wang Min. The teaching art of art [D]. Hunan Normal University, 2004

[2] Yang Jingjing. Introduction to artistic music classroom teaching [J]. Journal of Reading and Writing: Education Teaching Research, 2014, (10).

[3] Wang Tingting. How to use artistic techniques in the process of music teaching [J]. Journal of Popular Literature and Art, 2011, (2) : 247-247.

[4] Wan Qixue. Introduction to artistic music teaching [J]. Journal of Heihe Education, 2014, (3). 